\title{
Lead Halide Perovskite Nanocrystals: From Discovery to Self-assembly and Applications
}

\author{
Maksym V. Kovalenko§*ab and Maryna I. Bodnarchuk ${ }^{\text {ab }}$
}

§Werner Prize 2016

\begin{abstract}
Lead halide perovskites (LHPs) of the general formula APbX $\left(\mathrm{A}=\mathrm{Cs}^{+}, \mathrm{CH}_{3} \mathrm{NH}_{3}{ }^{+}\right.$, or $\mathrm{CH}\left(\mathrm{NH}_{2}\right)_{2}{ }^{+} ; \mathrm{X}=\mathrm{Cl}, \mathrm{Br}$, or I) have recently emerged as a unique class of low-cost, versatile semiconductors of high optoelectronic quality. These materials offer exceptionally facile solution-based engineerability in the form of bulk single crystals, thin films, or supported and unsupported nanostructures. The lattermost form, especially as colloidal nanocrystals (NCs), holds great promise as a versatile photonic source, operated via bright photoluminescence (PL) in displays or lighting (energy down-conversion of blue light into green and red), or via electroluminescence in light-emitting diodes. In this article we discuss the recent history of the development of highly-luminescent NCs of LHPs, the current state-of-the-art of this class of materials, and the future prospects of this highly active research field. We also report the demonstration of long-range ordered, self-organized superlattice structures obtained from cubeshaped colloidal $\mathrm{CsPbBr}_{3} \mathrm{NCs}$ using drying-mediated self-assembly.
\end{abstract}

Keywords: Colloids · Light-emitting devices · Metal halides · Nanocrystals · Perovskites · Photoluminescence · Television displays

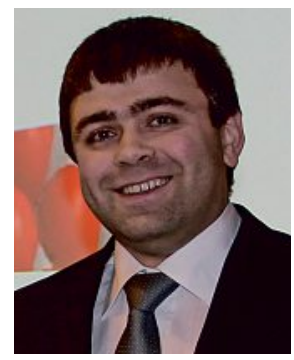

Maksym V. Kovalenko was a tenuretrack Assistant Professor of Inorganic Chemistry at ETH Zürich (Swiss Federal Institute of Technology) from July 2011 until January 2017 and has been an Associate Professor with tenure since then. His group is also partially hosted by Empa (Swiss Federal Laboratories for Materials

${ }^{\star}$ Correspondence: Prof. Dr. M. Kovalenko ${ }^{\mathrm{ab}}$ E-mail: mvkovalenko@ethz.ch ${ }^{a}$ ETH Zürich

aboratory of Inorganic Chemistry

Department of Chemistry and Applied Biosciences Vladimir-Prelog-Weg 1

$\mathrm{CH}-8093$ Zurich

${ }^{\circ}$ Empa- Swiss Federal Laboratories for

Materials Science and Technology

Laboratory for thin films and photovoltaics

Ueberlandstrasse 129

$\mathrm{CH}-8600$ Dübendorf
Science and Technology) to support his highly interdisciplinary research program. He studied chemistry as an undergraduate in Chernivtsi, Ukraine (1999-2004, Chernivtsi National University), which was followed by doctoral studies in Linz, Austria (2004-2007, Institute of Solid State Physics, Johannes Kepler University, with Prof. Wolfgang Heiss). He then undertook postdoctoral training in the United States (2008-2011, Department of Chemistry, University of Chicago, with Prof. Dmitri Talapin). His present scientific focus is on the development of new synthesis methods toward inorganic nanomaterials, and to control their surface chemistry and assembly into macroscopic solids. His ultimate, practical goal is to provide novel, high-performance inorganic materials for photonics and optoelectronics, as well as for rechargeable Li-ion batteries and post-Li-ion electrochemistries. Recently, his group pioneered the synthesis of highly luminescent colloidal nanomaterials of cesium lead halide perovskites, which hold great potential for applications in display technologies and lighting. With much larger forms of lead halide perovskites - centimeter-scale single-crystals - his group recently demonstrated the sensitive detection of hard radiation (X-rays and gamma photons).

So far, Prof. Kovalenko has been the recipient of an ERC Starting Grant (2012), the Ruzicka Preis (2013), and the Werner
Prize (2016). He has published over 130 articles in peer-reviewed journals, co-authored 3 book chapters, and is listed as an inventor in 11 patents.

\section{Introduction, History of LHPs, and the Discovery of LHP NCs}

Two fully independent research thrusts - namely, the roughly two-decades-long effort to control the synthesis and properties of colloidal nanoscale semiconductors and the recent breakthrough in photovoltaics that utilizes lead halide perovskites (LHPs) as light absorbers - have led our group to the development of the surfactantassisted hot-injection synthesis route to highly-luminescent colloidal nanocrystals (NCs) of fully inorganic LHPs, namely of $\mathrm{CsPbX}_{3}$ stoichiometry $(\mathrm{X}=\mathrm{Cl}, \mathrm{Br}$, or I). This topic has subsequently become one of the most active fields of research in materials chemistry, yielding over 1000 peer-reviewed research articles devoted to LHP NCs since early 2015. The time has come to carefully consider the brief history of this activity, make critical observations about its trajectory, and to guide future research by learning from the past.

Colloidal semiconductor NCs, often referred to as colloidal quantum dots (QDs), are sub-20 nanometer semiconductor crystallites synthesized in the colloidal state using inexpensive solution-phase chemis- 
try wherein the molecular precursors are reacted at $25-400{ }^{\circ} \mathrm{C}$. Surface capping ligands (also known as surfactants) are added to control the nucleation, growth, and long-term structural integrity of such colloidal NCs. Their electronic structure is intermediate between that of extended bulk solids and individual molecules, and is therefore size-tunable. A phenomenal level of control over the composition, morphology, surface chemistry, and self-assembly of colloidal NCs has been achieved over the last two decades, catalyzing a strong interest in and subsequently enabling applications in far-ranging fields such as optoelectronics $^{[1]}$ and the life sciences. ${ }^{[2]}$ Nearly all of the work thus far has focused on binary compounds, designated as II-VI ( $\mathrm{Zn}, \mathrm{Cd}, \mathrm{Hg}$ ), III-V (InP and InAs), and $\mathrm{IV}-\mathrm{VI}(\mathrm{Pb}$ and $\mathrm{Sn}$ chalcogenides), and multinary compounds (e.g. copper zinc tin sulfide, copper indium gallium selenide, etc.). ${ }^{[1,3]}$ It is worthwhile to note that semiconducting metal halides in the colloidal form have not received significant attention in this regard, even despite that non-colloidal luminescent copper halide nanocrystallites in glass matrices were reported long ago in pioneering studies on quantum-size effects. ${ }^{[4]}$ The major challenge facing semiconductor NCs has been to mitigate the detrimental electronic effects of their high surface area; under-coordinated surface sites and deviations from the bulk stoichiometry at the surface lead to the formation of trap states for charge carriers. As a consequence, semiconductor NCs are, generally speaking, poorly luminescent in the visible spectral range. The last 20 years of research have focused on either the efficient removal or rational control of these states, leading to the development of elaborate NC heterostructures (e.g. the concept of core-shell NCs) with bright photoluminescence (PL), and the directed surface functionalization of the NCs with both organic and inorganic capping agents for use in photodetectors and solar cells. The power conversion efficiencies of such solar cells are currently stagnant at $\sim 10 \%$ (PbS NCs), ${ }^{[5]}$ still largely if not solely limited by an incomplete understanding and control over the energy landscape of defect states. ${ }^{[\mathrm{b}]}$ Hence, semiconductor materials with surface defects that are not detrimental to their electronic structure would be seen as ideal candidates for colloidal semiconductor NCs, especially for performance in the visible and near-infrared spectral regions.

In parallel to work on colloidal semiconductor NCs, a significant discovery in the form of methyl ammonium lead iodide $\left(\mathrm{MAPbI}_{3}\right)$ as an outstanding PV material occurred in $2012^{[6]}$ and has been the subject of intense research activity ever since, leading to the demonstration of certified power conversion efficiencies in working PV cells of up to $22 \% .{ }^{[5]}$ Our research group made two key conclusions from this work that soon led us to the discovery of highly-luminescent $\mathrm{CsPbX}_{3} \mathrm{NCs}^{\text {[7] First, }}$ we recognized that LHPs must be highly defect-tolerant materials, i.e. that their structural defects (point defects, line defects, grain boundaries, and surfaces, etc.) are benign with respect to their electronic and optical properties. Second, we intuited that MA-based compounds would not be the best choice for making NCs due to their inherently poor chemical stability, which originates from their low energy of formation and volatile decomposition products, ${ }^{[8]}$ and which would be drastically further reduced upon downsizing. We thus focused on their fully inorganic analogues based on cesium $\left(\mathrm{CsPbX}_{3}\right)$ from the very beginning. In comparison to $\mathrm{MAPbX}_{3}$, these ternary compounds are far less soluble in common solvents. This is a drawback for direct solution processing but an advantage for producing colloidal NCs. In our pursuit of $\mathrm{CsPbX}_{3} \mathrm{NCs}$, we were further motivated by encouraging results reported between the early 1980s and the early 2000s wherein PL spectra were measured from Bridgman-grown single crystals and thermally evaporated thin films of $\mathrm{CsPbX}_{3}$ compounds, as well as for $\mathrm{Pb}$-doped cesium halide films. ${ }^{[9]}$ In particular, quantumsize effects and bright, narrow-band PL were reported for $\mathrm{Pb}$-doped $\mathrm{CsBr}$ films, indicating the inclusion of quantum-sized crystallites of $\mathrm{CsPbBr}{ }_{3}{ }^{[9 \mathrm{~d}-\mathrm{h}, 9 \mathrm{j}-1]}$
The name 'perovskite' traditionally applies to the isostructural oxide $\mathrm{ABO}_{3}$ compounds, such as the naturally-occurring mineral $\mathrm{CaTiO}_{3}$ (Fig. 1 (left)) which was discovered in 1838 in the Ural Mountains by Gustav Rose and Lev Perovski. The history of synthetic $\mathrm{CsPbX}_{3}$ compounds can also be traced back to the $19^{\text {th }}$ century (1893); ${ }^{[10]}$ however, the perovskite-type crystal structure (where the halide occupies the traditional oxide lattice site) was not established until later, in the 1950s. ${ }^{[11]}$ In the following decades, the crystal structures and phase transitions of $\mathrm{CsPbX}_{3}$ compounds were studied in great detail by $\mathrm{X}$-ray and neutron scattering, and by nuclear magnetic resonance spectroscopy. ${ }^{[9 \mathrm{j}, 12]}$ In the 1970s, Weber et al. synthesized and determined the crystal structures of the $\mathrm{MAPbX}_{3}$ compounds. ${ }^{[13]}$ All members of the $\mathrm{APbX}_{3}$ family $\left(\mathrm{A}=\mathrm{Cs}^{+}, \mathrm{CH}_{3} \mathrm{NH}_{3}^{+}\right.$, or $\mathrm{CH}\left(\mathrm{NH}_{2}\right)_{2}^{+} ; \mathrm{X}=\mathrm{Cl}, \mathrm{Br}$, or I) have since been obtained as solution-grown single crystals and thoroughly structurally characterized, including some with complex compositions such as with mixed-cationic and mixed-anionic occupations (Fig. 1 (center and right)). ${ }^{[14]}$

\section{Structure, Synthesis, Optical Properties, Stability, and Processability}

Unlike hard, thermally stable oxidic perovskites, LHPs are rather soft materials with low melting temperatures (all in the

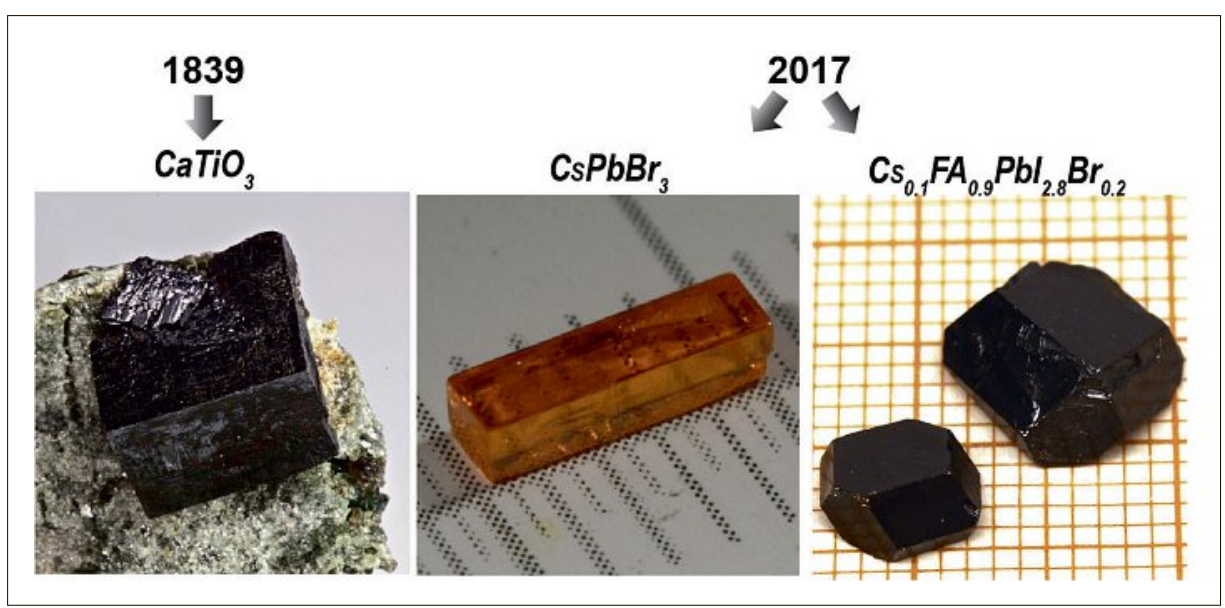

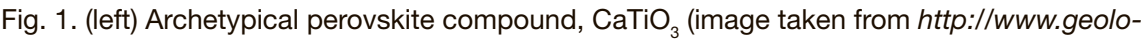
gypage.com/2014/06/perovskite. $h t m l, 4.5 \times 4.0 \times 2.0 \mathrm{~cm}$ ), a natural mineral occurring in the Ural Mountains (Russia), discovered and reported in 1839 by Gustav Rose and Lev Perovski. (middle) Synthetic lead halide perovskites, isostructural to natural titanium oxide perovskites, can be grown as cm-scale single crystals directly from solution. Rod-shaped $\mathrm{CsPbBr}_{3}$ single crystals (e.g. $1 \times 0.3 \times 0.3 \mathrm{~cm}$, shown here) with a bandgap energy in the visible spectral range $(2.25 \mathrm{eV})$ were grown by the inverse temperature crystallization method from highly concentrated solutions in a dymethylsulfoxide:dimethylformamide mixture under ambient air at temperatures of $90-110{ }^{\circ} \mathrm{C} \cdot[14 \mathrm{e}]$ Reprinted with permission from Chemistry of Materials, 2016, 28, 8470-8474. Copyright 2016 American Chemical Society. (right) Centimeter-large mixed-ion $\mathrm{Cs}_{0.1} \mathrm{FA}_{0.9} \mathrm{PbBr}_{2.8} \mathrm{I}_{0.2}$ single crystals with a bandgap energy in the near-infrared $(1.52 \mathrm{eV})$ were grown by the inverse temperature crystallization method from solutions in $\gamma$-butyrolactone at $80-130^{\circ} \mathrm{C} \cdot .^{[14]}$ Reprinted with permission from NPG Asia Materials 2017, 9, e373. Copyright 2017 Nature Publishing Group. 
range of $300-570{ }^{\circ} \mathrm{C}$ ). The crystal structure consists of $\left[\mathrm{PbX}_{6}\right]$ octahedra, connected in three dimensions by corner-sharing, as exemplified by orthorhombic $\mathrm{CsPbBr}_{3}$ (Fig. 1 (center), space group Pnma). The ionicity of bonding increases in the following series: (Si, Ge)-(GaAs, InP)-(CdTe, CdSe)(LHPs). The Phillips (spectroscopic) ionicity of GaAs is 0.321 and it drastically increases to $0.7-0.8$ for LHPs. As a result of this significantly ionic bonding character, the synthesis of LHP NCs is perhaps the simplest of all semiconductor NCs. It can be viewed as the arrested co-precipitation of ions in apolar media in the presence of long-chain capping ligands, as presented in the top panel of Fig. 2.[7] Experimentally speaking, Cs-oleate is rapidly injected into a warm solution of lead halide dissolved in octadecene containing oleic acid and oleylamine as capping ligands. Such reactions occur within several seconds, even at room temperature. Due to their nearly cubic unit cell, the resulting NCs are often formed as cubes (Fig. 2b, c). An alternative synthesis strategy, proposed by Schmidt et al. for $\mathrm{MAPbX}_{3} \mathrm{NCs}^{\left[{ }^{[15]}\right.}$ relies on the fast destabilization of molecular solutions; the lead halide source and alkylammonium halide are first dissolved in a 'good' solvent (e.g. one that is highly polar), often dimethylformamide (DMF), and then injected into a 'poor' (nonpolar) solvent such as toluene, containing the same surfactants (oleic acid and oleylamine). In the latter case, the nucleation of LHP NCs is initiated by the rapid reduction in solubility caused by the large amount of nonpolar solvent. Both synthesis methodologies are applicable to all $\mathrm{APbX}_{3}$ compounds and also allow for the synthesis of shapes other than cubes: e.g. nanowires ${ }^{[16]}$ and nanoplatelets. ${ }^{[17]}$ All LHP NCs, regardless of the method of their preparation, exhibit bright PL spanning the entire visible spectral range (Fig. 2e). In the case of $\mathrm{CsPbX}_{3} \mathrm{NCs}$, the line-widths of the PL bands are narrower than $100 \mathrm{meV}$ at all wavelengths. Furthermore, the PL

\section{$2 \mathrm{Cs}$-oleate $+3 \mathrm{PbX}_{2}$

$$
\underset{\text { Oleyl- } \mathrm{NH}_{2} / \text { oleic acid }}{\stackrel{140-200}{\circ} \mathrm{C}}
$$ \\ $2 \mathrm{CsPbX}_{3} \mathrm{NCs}+\mathrm{Pb}(\text { oleate })_{2}$}

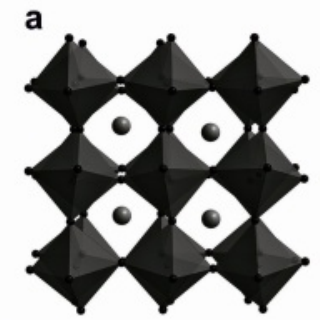

c
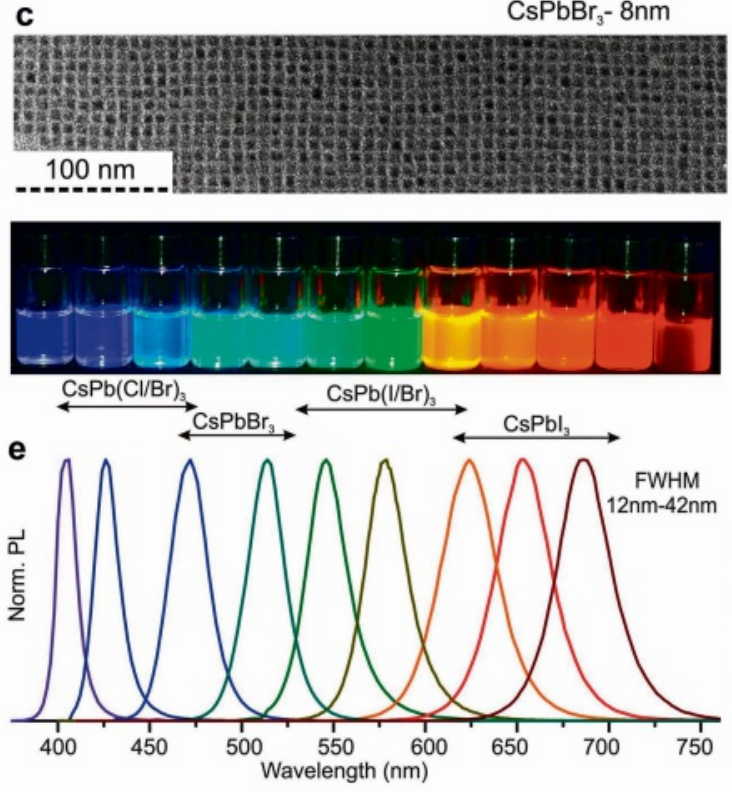

Fig. 2. Overview of the synthesis, characterization, and optical properties of $\mathrm{CsPbX}_{3} \mathrm{NCs}$ : (a) orthorhombic crystal structure of $\mathrm{CsPbX}_{3} ;(b, c)$ high- and low-magnification transmission electron micrographs of $\mathrm{CsPbBr}_{3} \mathrm{NCs}$; (d) X-ray diffraction patterns of $\mathrm{CsPbX}_{3} \mathrm{NCs}$; (e) representative PL spectra $\left(\lambda_{\text {exc }}=400 \mathrm{~nm}\right.$ for all except the $\mathrm{CsPbCl}_{3}$ samples where $\left.\lambda_{\text {exc }}=350 \mathrm{~nm}\right)$; (f) schematic of the electronic structure of $\mathrm{APbl}_{3} ;(\mathrm{g})$ photograph $\left(\lambda_{\text {exc }}=365 \mathrm{~nm}\right)$ of highly luminescent $\mathrm{CsPbX}_{3}$ NCs embedded in PMMA polymer monoliths obtained with Irgacure 819 as the photo-initiator for polymerization. Reprinted with permission from Nano Lett. 2015, 15, 3692-3696. Copyright 2015 American Chemical Society. quantum yields (QYs) reach nearly $100 \%$ in the green-red spectral range. Their radiative lifetimes fall into the nanosecond range, which is similar to conventional CdSe- or InP-based QDs. The major practical advantages of LHP NCs over conventional QDs relate to the absence of necessity to undertake electronic passivation in order to attain high PL QYs.

LHPs are considered to be direct-bandgap semiconductors and the states near the bandgap arise solely from the $\mathrm{X}$ and $\mathrm{Pb}$ atoms, whereas the A-site ions impart no substantial contribution (Fig. 2f). The valence band (VB) is primarily formed via the hybridization of $\mathrm{Pb} 6 \mathrm{~s}$ and halide p-orbitals, and the resulting antibonding states form the upper part of the VB. On the contrary, the conduction band $(\mathrm{CB})$ is formed primarily of empty $\mathrm{Pb} 6 \mathrm{p}$ states. High ionicity is reflected in the only marginal contribution of the halide orbitals to the CB. There is increasing evidence for the (likely dynamic) Rashba effect, ${ }^{[18]}$ i.e. band-splitting along inmomentum space, mediated by spin-orbit coupling and the breaking of inversion symmetry. The fast structural dynamics in centrosymmetric crystals lead to the required condition for the appearance of the dynamic Rashba effect, either extending over the whole crystal or fluctuating within the few-nm large domain.[18d] Such Rashba effects can explain their longer than expected carrier lifetimes, owing to carrier recombination that becomes phonon-assisted.

The major hurdles in the way of applications of LHP NCs arise from several forms of structural instability, and the quest for suitable mitigation strategies has become an increasingly important research activity. All LHPs are somewhat soluble in polar solvents, with $\mathrm{CsPbX}_{3}$ compounds being the least soluble. However, even seemingly negligible (but finite) solubility still represents a major threat to the structural integrity of the NCs. In addition, the binding of capping ligands in LHP NCs is highly dynamic, ${ }^{[19]}$ contrary to most conventional QDs, ${ }^{[20]}$ and hence the ligands quickly desorb upon isolation and intense purification, limiting their processability. Furthermore, the low melting points of LHPs render their densely packed assemblies susceptible to sintering. The encapsulation of individual LHP NCs by stable inorganics such as silica or alumina might resolve all three of these challenges togeth$\mathrm{er}$, as well as further enhance the oxidative stability. Several successes towards this goal should be highlighted. Firstly, LHP NCs were embedded into silica-alumina monoliths, formed by the controlled diffusion of moisture into a toluene solution containing LHP NCs and a single-source silica-alumina precursor, di-sec-butoxyaluminoxytriethoxysilane. ${ }^{[21]}$ Buonsanti 
et al. used atomic layer deposition for the precise growth of thin film alumina and other oxides on top of NC arrays, thereby rendering higher stability toward air, heat, light, and moisture. ${ }^{[22]}$ Finally, organic polymers with low oxygen and moisture transmission rates have been shown to serve as effective matrices for LHP NCs ${ }^{[23]}$ in addition to mesoporous silica matrices which have been demonstrated to be strong contenders as well.[24]

\section{Defects and Defect-tolerance in LHPs}

It is well established that even the widespread presence of native defects, which are abundant due to their low energy of formation, imparts no significant detrimental effects to the photophysics of LHP compounds. This high tolerance for defects arises from the fact that they reside in relatively shallow states within the bandgap. ${ }^{[25]}$ For example, in $\mathrm{CsPbBr}_{3}$ under Br-rich conditions, a vacancy on the Cs-site $\left(\mathrm{V}_{\mathrm{Cs}}\right)$ has a formation energy of $0.2 \mathrm{eV}$, the lowest of all possible defects. ${ }^{[26]}$ However, as shown in Fig. 2f, Cs-orbitals do not contribute to the near band-edge electronic structure and hence Cs vacancies are benign to the PL properties of $\mathrm{CsPbBr}_{3}$. Furthermore, vacancies on the halide sites, which appear as a result of Schottky-type defect formation (to maintain an equal number of cationic and anionic vacancies), are also non-detrimental to its electronic properties since the corresponding non-bonding $\mathrm{Pb}$ orbitals are resonant with the $\mathrm{CB}$ and the VB. Defects other than vacancies are characterized by much higher formation energies in perovskite lattices; it is difficult to displace the atoms, for example, by creating antistitial or interstitial defects. Understanding the origin of this apparent defect-tolerance and subsequently developing strategies for its design in novel semiconductors is an active topic of research. ${ }^{27]}$ At present, defect-tolerance is generally understood to be concomitant with the following attributes: high ionicity of bonding, significant $\mathrm{ns}^{2}$-character of the metal, small carrier capture cross sections (aided by low formal charges of the ions and high ionicity), and a crystal structure that suppresses cation orbital hybridization at the halide vacancy. Several computational studies have elucidated the origin of the strong immunity of $\mathrm{CsPbBr}$ towards point defects in the bulk material, ${ }^{[25]}$ at grain boundaries, ${ }^{[26]}$ and on NC surfaces. [28]

Due to the low formation energies of planar defects, $\mathrm{CsPbX}_{3} \mathrm{NCs}$ exhibit highly dynamic disorder; each $\mathrm{NC}$ is likely to consist of multiple crystalline domains of local orthorhombic symmetry separated

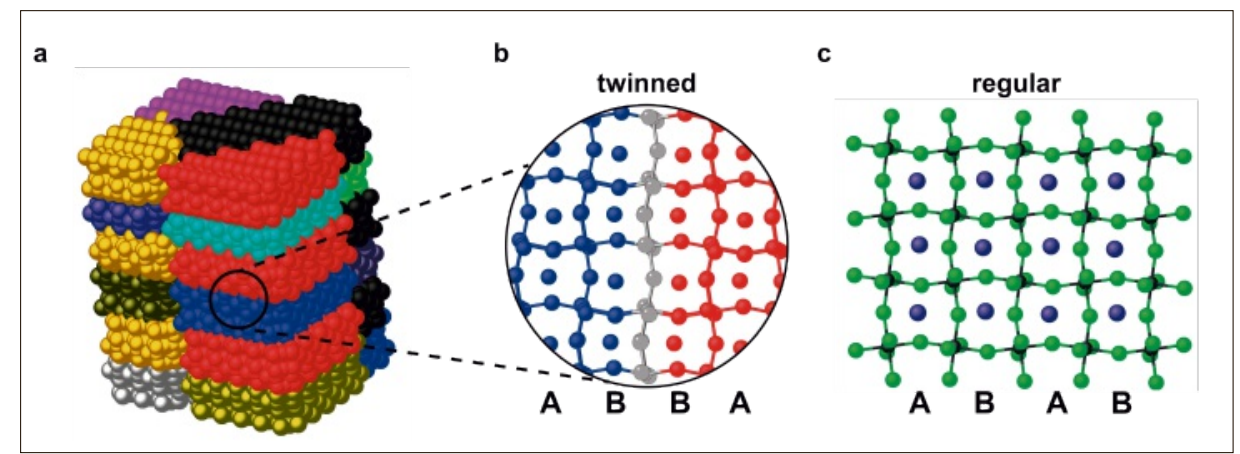

Fig. 3. Dynamic structural disorder in $\mathrm{CsPbBr}_{3} \mathrm{NCs}$ : (a) Atomistic model of a single $\mathrm{CsPbBr}_{3} \mathrm{NC}$ with multidomain structure, consistent with $\mathrm{X}$-ray total scattering data collected at $410 \mathrm{~K}$ and analyzed by the Debye scattering equation; (b) A single twin boundary connecting orthorhombic domains; (c) Normal orthorhombic lattice without any twin boundaries. Reprinted with permission from ACS Nano 2017, 11, 3819-3831. [29] Copyright 2017 American Chemical Society.

by twin planes (Fig. 3).[29] Twin boundaries do not disturb the sublattice of $\mathrm{Pb}$ ions, but instead correspond to the local rearrangement of halide ions. As a result, some low-intensity reflections of the orthorhombic lattice may vanish. Depending on the density and mutual orientation of the twin planes, the powder diffraction pattern can therefore appear to be cubic, orthorhombic, or tetragonal, especially when measured using a typical laboratory diffractometer.

\section{Self-assembly}

Self-organization is nature's most powerful tool for creating novel functional materials without using elaborate methods for the individual manipulation of building blocks. Monodisperse colloidal NCs are ideal inorganic building blocks with pre-designed functionalities; as well, a regular crystalline superstructure consisting of such building blocks - NC superlattices - is the most well-defined solid that can be prepared from individual NCs. In these superstructures, novel properties arising from the electronic and magnetic coupling between the NCs can be expected to arise. The forces that govern NC selfassembly range from hard- to soft-particle interactions. The self-organization of sterically-stabilized colloids (hard interparticle potentials), such as those formed by alkyl-chain capped NCs in apolar solvents, has thus far received the most attention. ${ }^{[30]}$ LHP NCs are an example of such a colloid. The transition from a disordered liquid state (with respect to the order between NCs) into an ordered superlattice is expected to occur during a late stage of the drying step. This transition is, perhaps counterintuitively, driven by an entropic factor as a result of the ordered state exhibiting a higher free-volume entropy, despite having a lower configuration entropy. Experimentally, the self-assembly of cubic LHP NCs can be realized by the controlled evaporation of the solvent (toluene) at room temperature on a hydrophobic glass or silicon substrate (Fig. 4). The addition of oleic acid and oleylamine (at a concentration of $1 / 1000$ with respect to toluene, by volume) was found to be essential for driving the outcome of self-organization towards the formation of cube-shaped and well-separated superlattice domains of $1-15 \mu \mathrm{m}$ in size. The NC concentration optimal for self-assembly is approx. $5 \mathrm{mg}$ / $\mathrm{mL}$. High monodispersity of the initial colloid of $9 \mathrm{~nm} \mathrm{CsPbBr}{ }_{3} \mathrm{NCs}$ (with a standard deviation in size of $<10 \%$ ), obtained by size-selective precipitation from the assynthesized batch of NCs, and high shape uniformity were found to be mandatory for obtaining long-range ordering in the resulting superlattices. The simple cubic packing of the nanocubes is readily apparent in transmission electron microscopy investigations of sub- $\mu \mathrm{m}$ scale domains. $\mathrm{CsPbBr}_{3} \mathrm{NCs}$ retain their bright PL in the superlattice state, with a slight red-shift due to the coupling between neighboring $\mathrm{NCs}$ and the dielectric effect.

\section{Towards Applications in Television Displays}

The liquid-crystal display (LCD) market, primarily for televisions (TVs) and monitors, is presently the most promising commercial opportunity for semiconductor NCs. It has been established that QDs can be used to simultaneously improve the energy efficiency of a display while enabling a broader palette of colors, approaching the complete spectrum visible to the human eye. Samsung is currently the market leader for QD-enhanced LCD displays. In such displays, InP-based QDs are incorporated into a backlight film, thereby allowing the conversion of a large portion of the blue light (460-470 nm) from InGaN light-emitting diodes (LEDs) into green $(\sim 530 \mathrm{~nm})$ and red $(630-640 \mathrm{~nm})$ light by means of efficient PL. In this capacity, 

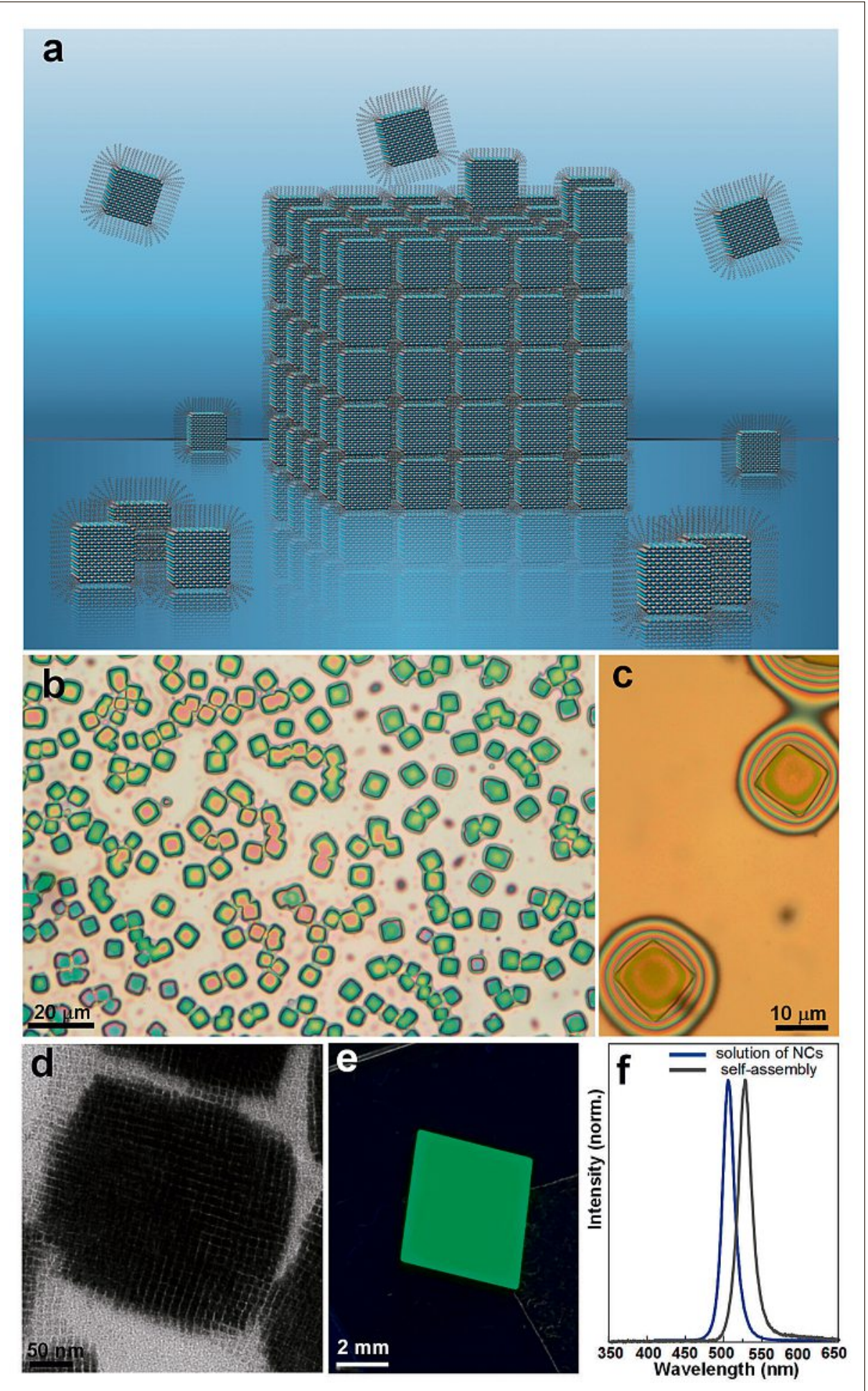

Fig. 4. Superlattices of $\mathrm{CsPbBr}_{3} \mathrm{NCs}$ : (a) Schematic of the drying-mediated self-organization of cubic $\mathrm{CsPbBr}_{3} \mathrm{NCs}$ into a simple cubic superlattice; (b, c) optical microscopy images after evaporation of the solvent; (d) transmission electron micrograph of a single superlattice; (e) photograph of green PL from a large area covered by NC superlattices; (f) PL spectra of $\mathrm{CsPbBr}_{3} \mathrm{NCs}$ before and after self-organization.

LHPs can be expected to serve as an attractive alternative. Three primary emitters (red, green, and blue, or RGB) constituting the output of the LCD backlighting are sufficient to reproduce any color within the Commission internationale de l'éclairage (CIE) 1931 color space chromaticity diagram by means of additive mixing. The narrow FWHMs of green and red prima- do fulfill the basic requirements for utilization in backlighting: tunable PL spectra, narrow emission linewidths, high PL QY, strong absorption at $\sim 460 \mathrm{~nm}$, short luminescence lifetimes (in the ns range), chemical processability and durability. Each of the three kinds, however, has its own set of advantages. InP is non-toxic, whereas CdSe and LHPs offer far better color purity (exhibiting a factor of 1.5-2 narrower emission linewidths), especially for the green primary. In 2017, it is estimated that $\sim 10$ million units of QD-enhanced TVs will be produced by Samsung, primarily in the high-price range of the overall selection offered. The main reason that QDs are not used in mid- to low-price range TVs is the high manufacturing cost of both the InP-based core-shell QDs as well as the barrier films needed to prevent the irreversible degradation of the QDs by oxygen and moisture. Toward this application, LHP NCs might be strong contenders to replace InP QDs. Appropriate accelerated aging tests are still necessary to ensure a device lifetime of 30,000 hours. The Swiss company Avantama Ltd. is presently a leader in the development of LHP NCs for displays; their backlight films have been demonstrated to sustain accelerated aging for 1,000 hours of testing at temperatures as high as $90{ }^{\circ} \mathrm{C}$, under high humidity and high blue flux, using inexpensive commercial barrier films with relatively high water vapor transmission rates (e.g. WVTR = $\left.10^{-2} \mathrm{gm}^{-2} \mathrm{day}^{-1}\right)$. With the current synthesis method employed, the installed capacity at Avantama Ltd. will allow for the fabrication of 1 million $\mathrm{m}^{2}$ of LHP NC-based backlight film.

Besides conventional backlighting, the display industry is also working on new concepts for QD-displays. One problem with backlighting is that up to two thirds of the light is lost by color filtering. One approach to avoid this loss, which also circumvents the necessity for color filters, is to use QD-based pixels in front of the LCD panel (Fig. 5b). The first TV displays employing this concept, referred to as a QDcolor filter (QD-CF), are expected to reach the market in 2018 or 2019.

In the longer term, LHP NCs also hold great promise for direct electricity-to-light conversion (i.e. electroluminescence) in LEDs. The main advantage of a QD LED display would be its low manufacturing cost due to the printability of QD LED pixels and the simple display architecture. Exciton binding energies, which substantially influence the efficiency of the electroluminescence, can be engineered by quantum-size effects. While exciton binding energies in bulk $\mathrm{CsPBr}_{3}$ are estimated to be $33 \mathrm{meV},{ }^{[31]}$ they can increase to 50 $\mathrm{meV}$ in small NCs $(5.5 \mathrm{~nm})^{[32]}$ and further to $120 \mathrm{meV}$ in $3.4 \mathrm{~nm}$ thick $\mathrm{CsPbBr}_{3}$ 

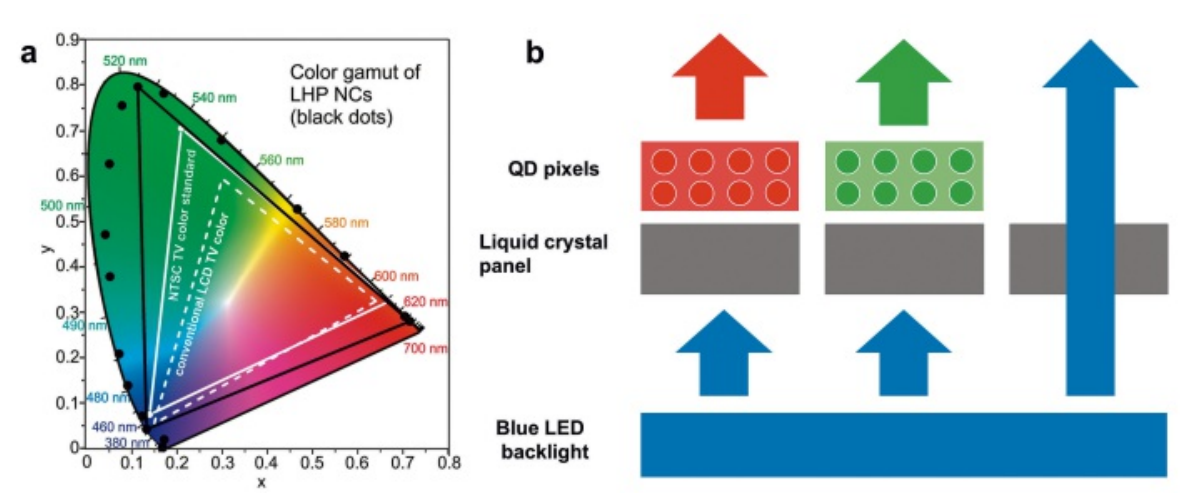

Fig. 5. Towards applications of LHP NCs in LCD displays: (a) Color gamut of $\mathrm{CsPbX}_{3} \mathrm{NCs}$ (black points) plotted on the CIE 1931 color space chromaticity diagram, compared to common color standards (LCD TV, dashed white line, and NTSC TV, solid white line). Reprinted with permission from Nano Lett. 2015, 15, 3692-3696. Copyright 2015 American Chemical Society. (b) Schematic of the QD-color filter (QD-CF) concept for LCD displays. A blue backlight is converted into green and red light by luminescent QD-containing pixels. The red and green QDs are required to absorb at least $99 \%$ of the incident blue light at a maximum QD pixel layer thickness of $5 \mu \mathrm{m}$. In this respect, LHP NCs outperform core-shell CdSe or InP QDs by a factor of 3-6. The figure is courtesy of Avantama Ltd. (Stäfa, Switzerland).

nanoplatelets. ${ }^{[33]}$ In green $\mathrm{CsPbBr}_{3}$ and red $\mathrm{CsPb}_{3} \mathrm{NCs}$, external quantum efficiencies (EQEs) of up to 6-9\% and a peak luminance of over $15,000 \mathrm{~cd} / \mathrm{m}^{2}$ have been demonstrated. ${ }^{[34]}$ It remains far more difficult to achieve efficient blue-emissive LEDs, where the highest EQEs of $1.9 \%$ and $0.61 \%$ were reported for $\mathrm{CsPbBr} \mathrm{Cl}_{3-\mathrm{x}}$ $\mathrm{NCs}$ (at $490 \mathrm{~nm}$ ) ${ }^{[35]}$ and $\mathrm{CsPbCl}_{3} \mathrm{NCs}_{\text {(at }}$ $405 \mathrm{~nm}),{ }^{[34 \mathrm{c}]}$ respectively. The low efficiencies and, especially, the limited stability of LEDs made from conventional QDs and from LHPs leave the forecast for their eventual commercialization highly uncertain. Many issues remain to be resolved: the specific LHP NC surface chemistry is not well understood and controlled, carrier injection must be balanced, appropriate hole-transporting materials are not well established, etc. Notably, after 20 years of research, CdSe-based NC LEDs have finally demonstrated EQEs in excess of $20 \%$, ${ }^{36]}$ but there are still no suitable prototype displays, highlighting the significance of the other issues.

The better the quality of the RGB primaries in a display, the harder it is to faithfully reproduce cyan and yellow colors, as perceived by human eyes. In solely RGB backlighting, cyan color results from combining blue and green, while yellow results from combining green and red. This stems directly from the nature of color perception by the short, medium, and long cone cells in the visual cortex of the brain. However, the yellow color created by mixing of RGB primaries is not perceived by human eye as faithful to true yellow $(\sim 580 \mathrm{~nm})$. The perceived difference is greater when the green and red primaries are narrower in linewidth. A similar problem exists for the cyan region. This issue has been addressed by Do et al. who have shown that LHP NCs have the unique potential to be applied in multicolor display concepts, such as in sixcolor LED backlighting where the 'perception gaps' pertaining to cyan and yellow can be effectively closed. ${ }^{[37]}$ In their example, three additional mixed-halide LHP NCs with cyan, yellow-green, and orange emissions were added to the standard RGB primaries.

\section{Other Prospective Applications}

A closely related application to QDenhanced LCDs is the utilization of fluorescent NCs in lighting. The facile color-tuning and color-purity of LHP NCs together allow the precise adjustment of emitted light in the spectrum relevant to room lighting. ${ }^{[38]}$ The stability requirements for lighting applications are, however, significantly higher, and may never be fulfilled by QDs of any type because of the several orders of magnitude higher blue flux and higher temperatures of 100-200 ${ }^{\circ} \mathrm{C}$ encountered during operation.

LHP NCs offer facile compositional tunability of both the emission wavelengths and the PL lifetimes. Wellestablished fluorescence lifetime imaging (FLIM), a mature technology that has already been demonstrated to work using visible- and near-infrared-emissive QDs as sensors and tags, ${ }^{[39]}$ is therefore an attractive potential application for LHP NCs. FLIM with conventional QDs has also attracted considerable attention for security purposes, ${ }^{[40]}$ with obvious applications in items such as banknotes, branded goods, and drug and food packaging. The narrow and symmetric PL spectra of LHP NCs are difficult to reproduce with other materials. In particular, infrared-emissive LHP
NCs possess FWHMs of typically $40 \mathrm{~nm}$, making them very difficult to imitate with conventional dye molecules. PL barcoding can be achieved by a variety of methods, such as by direct ink-jet printing of NCs or NC-containing beads, as well as by mixing different NCs, including those with magnetic or plasmonic functionalities. Encapsulation techniques within low WVTR polymers are particularly promising for ensuring their long-term stability. Similarly as for display applications, narrow FWHMs of emission are preferred for such barcoding applications. Theoretically, the number of achievable color combinations can be estimated as $n^{m}$, where $\mathrm{n}$ is the number of intensities and $m$ is the number of emission bands. ${ }^{[42]}$ In the PL spectral range of 400-800 nm, LHP NCs exhibit FWHMs of less than $100 \mathrm{meV}$ (i.e. FWHM = 12 at $400 \mathrm{~nm}$, and FWHM $=50 \mathrm{~nm}$ at $800 \mathrm{~nm}$ ); this would yield up to 10,000 unique barcodes which could be detected with conventional, lowcost spectrometers. The applications of PL barcoding can range widely, from use in commercial packaging, to banknotes, personal identification documents (e.g. passports and driver's licenses), and security papers. ${ }^{[43]}$

Colloidal NCs have traditionally been considered promising for applications in amplified stimulated emission (ASE), which would be required to develop novel inexpensive lasers. Optically pumped ASE using pulsed lasers has been demonstrated in densely packed films of LHP NCs, ${ }^{[44]}$ covering the entire visible spectral range (Fig. 6) and showing pumping threshold fluencies as small as those obtained by the best Cd-chalcogenide QDs and quantum platelets. The chalcogenides, however, still suffer from poor stability in the blue spectral region $(\leq 500 \mathrm{~nm}){ }^{[45]}$ High optical gain values of up to $450 \mathrm{~cm}^{-1}$ were estimated.[44a] Let us compare the lasing thresholds that have been achieved, to present, for various QD compounds (where all fluencies are for typical femtosecond lasers used for excitation). $\mathrm{CdSe} / \mathrm{ZnCdS}$ core-shell QDs have been demonstrated to allow for thresholds of $90 \mu \mathrm{J} \mathrm{cm}^{-2}$ for red QDs and up to 800 $\mu \mathrm{J} \mathrm{cm}^{-2}$ for blue QDs, with single-exciton optical gain. ${ }^{[46]} \mathrm{CdSe}$ and core-shell $\mathrm{CdSe} /$ CdS nanoplatelets ${ }^{[47]}$ have been shown to exhibit the lowest thresholds of all colloidal chalcogenide NCs $\left(6 \mu \mathrm{J} \mathrm{cm} \mathrm{cm}^{-2}\right.$ at 520 $\mathrm{nm}$ and $8 \mu \mathrm{J} \mathrm{cm}^{-2}$ at $\left.635 \mathrm{~nm}\right) .{ }^{[47 \mathrm{c}, 48]}$ Unlike Cd-chalcogenides, strongly quantumconfined $\mathrm{CsPbBr}_{3} \mathrm{NCs}$ exhibit up to an order of magnitude higher ASE thresholds. Weakly-confined $\mathrm{CsPbX}_{3}$ NCs $(\geq 10 \mathrm{~nm})$ exhibit ASE thresholds of $\leq 10 \mu \mathrm{J} \mathrm{cm}^{-2}$ in the green-blue range. The appearance of the ASE peak at a lower energy than the PL peak suggests a biexcitonic mechanism of lasing in LHP NCs. Two kinds 
of lasing modes have been realized with densely packed $\mathrm{CsPbX}_{3}$ films: whispering gallery mode (WGM) lasing using silica microspheres as high-finesse resonators, conformally coated with $\mathrm{CsPbX}_{3} \mathrm{NCs}$ (Fig. 6c), and random lasing in films of $\mathrm{CsPbX}_{3} \mathrm{NCs}^{[44 \mathrm{a}]}$

With nanosecond excitation pulses, ASE thresholds for $\mathrm{CsPbBr}_{3} \mathrm{NC}$ films increase to $\sim 0.5 \mathrm{~mJ} \mathrm{~cm}^{-2}$. Two-photon absorption can also be utilized to achieve $\mathrm{ASE}$ in $\mathrm{CsPbX}_{3} \mathrm{NCs}$ (corresponding to thresholds of $\left.\sim 0.8 \mathrm{~mJ} \mathrm{~cm}^{-2}\right)$. ${ }^{[49]}$ In comparison to colloidal LHPs, non-colloidal, templated LHP nanowires exhibit even lower lasing thresholds below $1 \mu \mathrm{J} \mathrm{cm}^{-2},{ }^{[50]}$ presumably due to the fact that an optimally sized, flat-surface nanowire can itself act as a waveguide and high-quality-factor microresonator. Continuous-wave optical or electrically-driven lasing remains elusive for colloidal LHP NCs and LHPs in general, and will certainly remain a major research objective in the near future.

We remain assured that LHP NCs will find their place in the future materials landscape that will be required to meet the increasing demand for connectivity and multifunctionality, sometimes referred to as the 'internet of things'. For example, anisotropic NC-based LEDs can offer not only the regular functionality of LEDs (i.e. electroluminescence), but also polarization of the emitted light as well as PV light detection capability. This could perhaps enable fast display-to-display communication. ${ }^{[51]}$

\section{LHP Chemistry beyond APbX Compounds: 2D Perovskites}

The 3D polymorphs of $\mathrm{APbX}_{3}$ compounds, the principal topic of this review, are inherently restricted to three A-site cations $\left(\mathrm{Cs}^{+}, \mathrm{FA}\right.$, and MA) due to geometric factors (known as the Goldschmidt Tolerance Factor). However, the compositional and structural variability can be greatly extended by the consideration of 2D perovskites (Fig. 7), wherein larger A-site cations can be incorporated. To this end, primary alkylammonium salts are typically employed as the A-site cations, forming $2 \mathrm{D}$ perovskites of the formula $\left(\mathrm{RNH}_{3}\right)_{2} \mathrm{MX}_{4}$, wherein extended layers of corner-sharing octahedra are separated by organic spacers. A typical example is that of $\left(\mathrm{n}-\mathrm{C}_{4} \mathrm{H}_{9} \mathrm{NH}_{3}\right)_{2} \mathrm{PbI}_{4}$ (Fig. 7a). The nonspherical shape of $\mathrm{RNH}_{3}^{+}$is paramount for obtaining the $2 \mathrm{D}$ perovskite crystal symmetry and octahedral distortions. ${ }^{[52]}$ The ammonium groups form hydrogen bonds with neighboring halogen ions. The fundamental physics of these compounds combines macroscopically extended charge-carrier delocalization and transport with strong quantum confinement in one-dimension, making such compounds perfect quantum wells. Correspondingly, the excitonic binding energies are greatly increased (from several meV to hundreds of meV), which, combined with their inherent defect-tolerance, opens exciting opportunities for LEDs and other optoelectronic applications. When a mixture of two cations is employed (where one is bulky and the other is MA or FA), the 2D analogues to perovskite Ruddlesden-Popper phases can form, as in the case of $\left(\mathrm{RNH}_{3}\right)_{2}\left(\mathrm{CH}_{3} \mathrm{NH}_{3}\right)_{\mathrm{n}-1} \mathrm{~Pb}_{\mathrm{n}} \mathrm{X}_{3 \mathrm{n}}$ $\left(\mathrm{R}=\mathrm{C}_{4} \mathrm{H}_{9}, \mathrm{C}_{9} \mathrm{H}_{19}-\right.$ or $\mathrm{Ph}-\mathrm{CH}_{2} \mathrm{CH}_{2}-, \mathrm{X}^{-}=$ $\mathrm{Br}^{-}$or $\left.\mathrm{I}^{-}\right) .{ }^{[53]}$ In such structures, 3D-like slabs, with small $\mathrm{CH}_{3} \mathrm{NH}_{3}{ }^{+}$ions filling the A-site voids, are separated by boundaries containing the bulkier cation. Further details about the structural chemistry of such compounds can be found elsewhere.[54]
In $\left(\mathrm{C}_{4} \mathrm{H}_{9} \mathrm{NH}_{3}\right)_{2}\left(\mathrm{CH}_{3} \mathrm{NH}_{3}\right)_{\mathrm{n}-1} \mathrm{~Pb}_{\mathrm{n}} \mathrm{I}_{3 \mathrm{n}+1}$, the bandgap energies change from 2.43 to 1.91 $\mathrm{eV}$ and then to $1.5 \mathrm{eV}$ as the thickness is adjusted from $n=1$ to $n=4$ and up to $n=\infty$, ${ }^{[53 b]}$ with the lattermost case corresponding to bulk $\mathrm{CH}_{3} \mathrm{NH}_{3} \mathrm{PbI}_{3}$. The remaining issue with such layered perovskites is the chemical instability of $\mathrm{CH}_{3} \mathrm{NH}_{3}$, enhanced by the volatility of the decomposition products (e.g. $\mathrm{CH}_{3} \mathrm{NH}_{2}$, $\mathrm{HI}$, etc.), which worsens upon exposure to moisture, as in ambient air. ${ }^{[55]}$ With the aim of fully eliminating primary, secondary, and ternary alkyl amines from the structure of layered LHPs, our group completely replaced the unstable $\mathrm{CH}_{3} \mathrm{NH}_{3}{ }^{+}$ions with a mixture of $\mathrm{Cs}^{+}$and guanidinium $\left(\mathrm{C}\left(\mathrm{NH}_{2}\right)_{3}^{+}\right)$ ions. The latter is the smallest alternative to MA and FA that is also stable, is very basic ( $\mathrm{pK}=13.6)$, and contains strong hydrogen-bonding capabilities. While the $\left(\mathrm{C}\left(\mathrm{NH}_{2}\right)_{3}\right)^{+}$ion can be accommodated only in the interlayer space, the small $\mathrm{Cs}^{+}$ion is universally suited for both interlayer locations as well as for occupying the voids between the octahedra. This effort has led to the development of the single-layer and double-layer 2D perovskites presented in Fig. 7b,c (further details will be published elsewhere): $\mathrm{Cs}\left[\mathrm{C}\left(\mathrm{NH}_{2}\right)_{3}\right] \mathrm{PbBr}_{4}$ (I), $\mathrm{Cs}_{2}\left[\mathrm{C}\left(\mathrm{NH}_{2}\right)_{3}\right] \mathrm{Pb}_{2} \mathrm{Br}_{7}(\mathbf{I I})$, and $\mathrm{Cs}\left[\mathrm{C}\left(\mathrm{NH}_{2}\right)_{3}\right]$ $\mathrm{PbI}_{4}$ (III, isostructural to I). All of these compounds contain alternating $\mathrm{Cs}^{+}$and $\left[\mathrm{C}\left(\mathrm{NH}_{2}\right)_{3}\right]^{+}$ions in the inter-slab spacing. Interestingly, in the absence of $\mathrm{Cs}^{+}$ ions, a flat layered structure cannot be formed. $\left[\mathrm{C}\left(\mathrm{NH}_{2}\right)_{3}\right]_{2} \mathrm{PbBr}_{4}$, for instance, consists of $1 \mathrm{D}$ chains of corner-sharing $\left[\mathrm{PbBr}_{5}\right]$ square pyramids, whereas $\left[\mathrm{C}\left(\mathrm{NH}_{2}\right)_{3}\right]_{2} \mathrm{PbI}_{4}$ does form a 2D lattice, but unlike $\mathrm{Cs}\left[\mathrm{C}\left(\mathrm{NH}_{2}\right)_{3}\right] \mathrm{PbI}_{4}$, it consists of corrugated (zig-zag) layers. It should be noted that all Cs-guanidinium 2D LHP

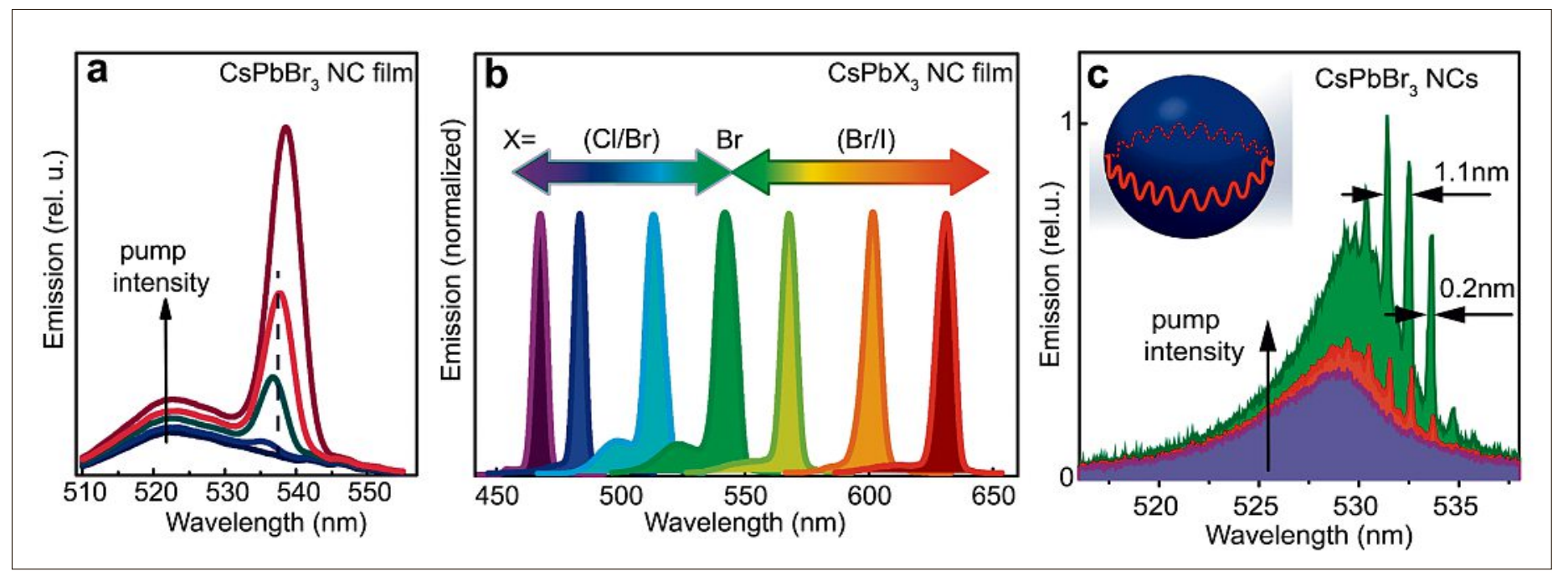

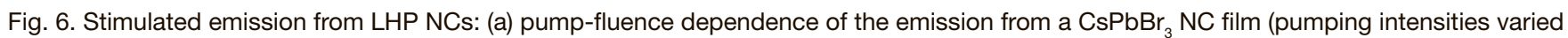
between 3-25 $\mu \mathrm{J} \mathrm{cm}^{-2}$ ); (b) spectral tunability of ASE via compositional modulation of $\mathrm{CsPbX}_{3} \mathrm{NC}$ films; (c) evolution from PL to whispering-gallery-mode (WGM) lasing with increasing pump intensity in a silica microsphere resonator of $15 \mu \mathrm{m}$ diameter, covered by a film of $\mathrm{CsPbBr}{ }_{3} \mathrm{NCs}$. Reproduced with permission from Nat. Commun. 2015, 6, 9056. ${ }^{[44]}$ Copyright 2015 Nature Publishing Group. 
compounds exhibit high thermal stability (up to $300{ }^{\circ} \mathrm{C}$ ).

The fundamental electronic structure of such layered LHPs is reflected in their optical absorption spectra. This is presented herein by the Kubelka-Munk function (Fig. 7d), $F\left(R_{\infty}\right)$, which can be estimated as $F\left(R_{\infty}\right)=\alpha / S=\left(1-R_{\infty}\right)^{2} / R_{\infty}$, where $\alpha$ is the absorption coefficient, $S$ is the scattering coefficient, and $R$ is the measured reflectance of the powdered sample. All 2D LHP compounds exhibit a sharp excitonic peak. The degree of excitonic confinement decreases with increasing thickness of the Pb-halide slabs (I vs. II). The bandgap energy also becomes lower for heavier halides (I vs. III). When comparing various spacer molecules, such as between butylammonium (as in a fourth compound, $\left(\mathrm{n}-\mathrm{C}_{4} \mathrm{H}_{9} \mathrm{NH}_{3}\right)_{2} \mathrm{PbBr}_{4}$, IV) and the much smaller Cs-guanidinium mixture (I), the bandgap energy of the latter is $\sim 0.2 \mathrm{eV}$ smaller due to reduced electronic isolation. Compounds I-III are all luminescent, as exemplified by compound II as shown in Fig. 7e. 2D-delocalization of the carriers in these compounds is confirmed by their efficient photoresponsivities, achieving values in the range of $1-10 \mathrm{~mA} \cdot \mathrm{W}^{-1}$ with narrowband characteristics (Fig. 7f). Since $\mathrm{Cs}^{+}$ and $\mathrm{C}\left(\mathrm{NH}_{2}\right)_{3}{ }^{+}$are popular additives in LHP thin films for $\mathrm{PV}$, studies of $2 \mathrm{D}$ perovskites might also have a cross-community impact as they shed light onto the possible crystal phases present in polycrystalline thin-films used to construct solar cells.

\section{Outlook}

With regard to the chemistry of LHPs, we envision two major research foci of the next several years. The first is the stabilization of LHP NCs by means of their embedding into stable matrices or coating with protective organic and inorganic shells. Because of the toxicity hazard inherent to lead, the second major topic will be the replacement of LHPs with non-toxic elements that can faithfully reproduce the unique photophysics of LHPs. This second task has thus far been mainly undertaken by the photovoltaic community; most reports are of computational screening efforts, while experimental successes showing new materials with LHP-like properties in nontoxic metal halides remain elusive. ${ }^{[27,56]}$ A cross-community impact on the field of semiconductor NCs is expected to result from this work. The most obvious approach, the replacement of $\mathrm{Pb}^{2+}$ with $\mathrm{Sn}^{2+}$ and $\mathrm{Ge}^{2+}$, is limited by the propensity of these ions toward oxidation. Most attention has therefore been devoted to the cationic transmutation in so-called double perovskites, i.e. the replacement of divalent $\mathrm{Pb}^{2+}$ with a mixture of mono- and tri-

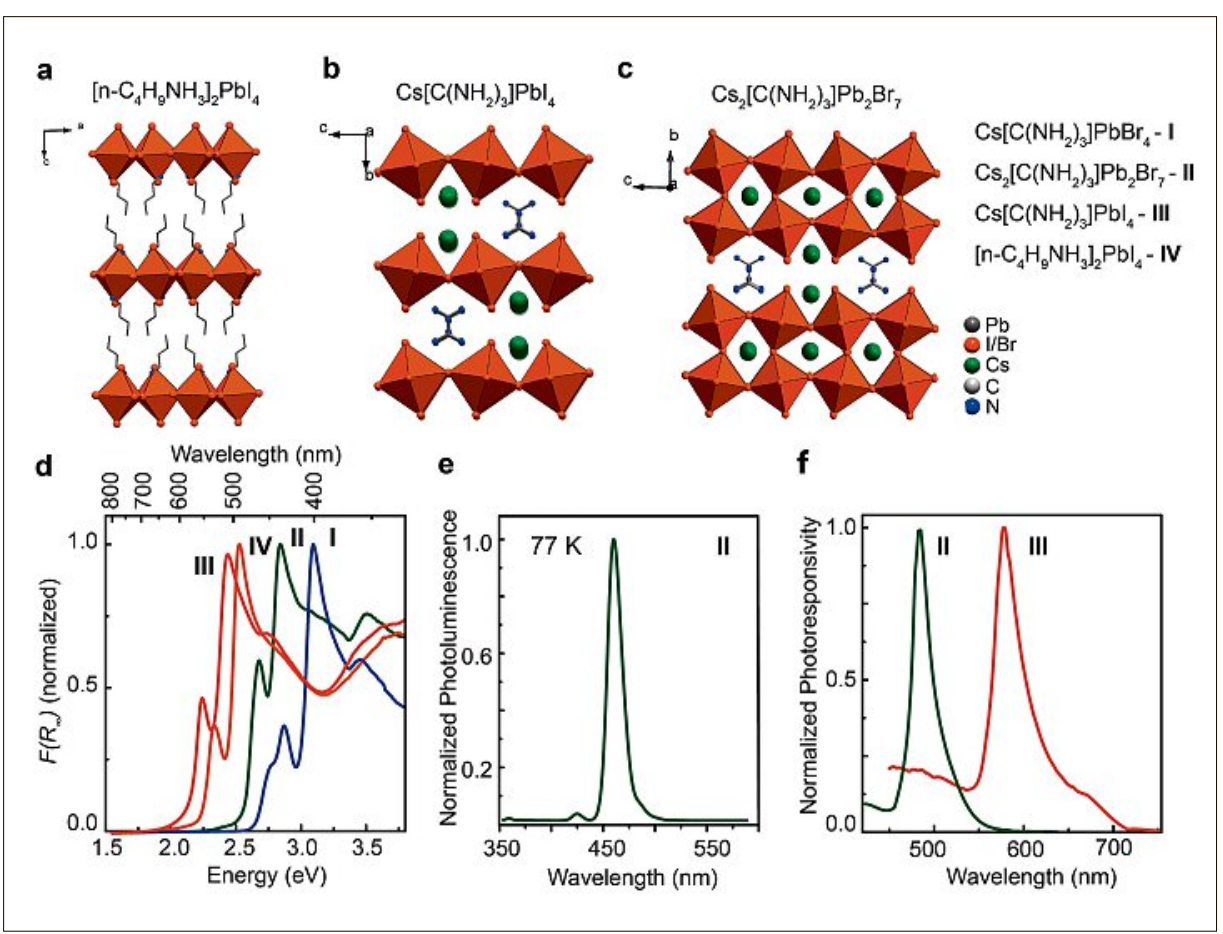

Fig. 7. Layered LHPs as natural quantum wells. (a, b, c) Crystal structures of $\left(n-\mathrm{C}_{4} \mathrm{H}_{9} \mathrm{NH}_{3}\right)_{2} \mathrm{PbBr}_{4}$ (IV), $\mathrm{Cs}\left[\mathrm{C}\left(\mathrm{NH}_{2}\right)_{3}\right] \mathrm{Pbl}_{4}$ (III), and $\mathrm{Cs}_{2}\left[\mathrm{C}\left(\mathrm{NH}_{2}\right)_{3}\right] \mathrm{Pb}_{2} \mathrm{Br}_{7}$ (II). (d) Optical absorption spectra of compounds I-IV, represented by the Kubelka-Munk function, $F\left(R_{\infty}\right)=\left(1-R_{\infty}\right)^{2} / R_{\infty}$ (where $R_{\infty}$ is diffusive reflectance). (e) PL spectrum of compound (II) measured at 77 K. (f) Room-temperature photoconductivity of single crystals of compounds II and III. The figure is courtesy of O. Nazarenko. The full study is currently under review in Inorganic Chemistry (American Chemical Society).

valent cations, with the intention of homogeneously distributing these two ion types on the Pb-sites. ${ }^{[57]}$ Zunger et al. have computationally studied $\mathrm{Cu}$-In and Ag-In halide double perovskites such as $\mathrm{Rb}_{2}$ [CuIn] $\mathrm{Cl}_{6}, \mathrm{Rb}_{2}[\mathrm{AgIn}] \mathrm{Br}_{6}$, and $\mathrm{Cs}_{2}[\mathrm{AgIn}] \mathrm{Br}_{6}{ }^{[57 \mathrm{c}]}$ Overall, several dozen $\mathrm{A}_{2} \mathrm{M}^{+} \mathrm{M}^{3+} \mathrm{X}_{6}$ compounds were predicted to possess general thermodynamic stability and suitable bandgap energies of 1-2 eV, as well as small carrier masses and small exciton binding energies. ${ }^{[57 d]}$ Experimental studies have demonstrated the stability toward ambient conditions and the direct-bandgap nature of $\mathrm{Cs}_{2} \mathrm{AgInCl}_{6}\left(\mathrm{E}_{\mathrm{g}}=3.3 \mathrm{eV}\right)$. [57b] At this stage, more experimental work is needed to clarify the practical potential of double perovskites. Typical issues include the photoinstability of $\mathrm{Ag}(\mathrm{I})$-containing perovskites and indirect bandgaps, such as in $\mathrm{Cs}_{2} \mathrm{AgBiBr}_{6} \cdot{ }^{[57 \mathrm{a}]} \mathrm{A}$ computational study by Yan et al. that accounts for the possibility of inversion symmetry-induced parityforbidden transitions has suggested that only those double perovskites that have $\mathrm{M}^{+}=\mathrm{In}$ or $\mathrm{Tl}$ and $\mathrm{M}^{3+}=\mathrm{Sb}$ or $\mathrm{Bi}$ might have a direct bandgap and other properties desired for solar cells and optoelectronic applications. ${ }^{[58]}$

Brandt et al. ${ }^{[27 a]}$ have used the measured radiative lifetimes, directly related to the minority carrier lifetimes, as a selection criterion, in addition to the bandgap energy, for determining potential for PV applications. For example, there are only three kinds of typical direct-bandgap photovoltaic absorbers, namely $\mathrm{Cu}(\mathrm{In}, \mathrm{Ga}) \mathrm{Se}_{2}$, CdTe, and LHPs, which possess bulk lifetimes in excess of $100 \mathrm{~ns}$; all three achieve PV power conversion efficiencies above $20 \%$. Brandt et al. identified InI, SbSI, SbSeI, and $\mathrm{BiOI}$ as prospective materials with PL lifetimes of at least $1 \mathrm{~ns}$. If the desired functionality is PL, an extended metal-halide framework might not be necessary at all, as was recently demonstrated with the infrared-luminescent OD perovskite compound $\mathrm{Cs}_{2} \mathrm{PdBr}_{6} \cdot{ }^{[59]}$

Beyond $\mathrm{AMX}_{3}$ and $\mathrm{AM}^{1+} \mathrm{M}^{3+} \mathrm{X}^{3}$ archetypes, another class of materials is of interest: namely, those with antiperovskite crystal structure. In $\mathrm{M}_{3} \mathrm{AB}$ and related compounds, the crystallographic positions of the cations and anions are reversed. Oxides form antiperovskites naturally, such as $\mathrm{Ca}_{3}\left(\mathrm{SiO}_{4}\right) \mathrm{O}$. Known, synthetic antiperovskite halide compounds include $M=\mathrm{Mn}, \mathrm{Ni}$, and $\mathrm{Fe}$ and $A=\mathrm{Ga}, \mathrm{Cu}, \mathrm{Sn}$, and $\mathrm{Zn} ; B=\mathrm{N}, \mathrm{C}, \mathrm{B}$ and halide. Notable recent examples of antiperovskite halides are $\mathrm{TlSn}_{2} \mathrm{I}_{5}$ (a semiconductor) ${ }^{[60]}$ and $\mathrm{Li}_{3} \mathrm{OCl}$ (a dielectric, Li-ion conductor). ${ }^{61]}$ A more complex compound is $\mathrm{Ba}_{3}\left(\mathrm{FeS}_{4}\right) \mathrm{Br}$ (a ferromagnetic semiconductor). ${ }^{[62]}$ In the lattermost example, the $\left[\mathrm{Ba}_{3} \mathrm{Br}\right]$ octahedral network is filled by large A-site $\mathrm{FeS}_{4}$ tetrahedra. Overall, chalco-halides clearly deserve broad attention and experimental efforts. 


\section{Acknowledgments}

M.V. K. is very grateful to his former and present co-workers and collaborators, whose names can be found on joint publications. In particular, LHP-related work in the Functional Inorganic Materials group has been greatly advanced through the dedicated work of Loredana Protesescu, Sergii Yakunin, Olga Nazarenko, Georgian Nedelcu, Franziska Krieg, Dmitry Dirin and numerous undergraduate and master students. M.V.K. thanks Avantama Ltd, in particular Norman Lüchinger, Marek Oszajca and Stefan Loher, for contribution to the section on displays and for collaboration. This work was financially supported by the European Research Council under the European Union's Seventh Framework Program (Grant Agreement Nr. 306733, ERC Starting Grant 'NANOSOLID') and by the Swiss Federal Commission for Technology and Innovation (CTI-No. 18614.1 PFNM-NM). M.B. Acknowledges the Swiss National Science Foundation (SNF Ambizione Energy grant, Grant Nr. PZENP2_154287). Electron microscopy was performed at the Empa Electron Microscopy Center and at the Scientific Center for Optical and Electron Microscopy (ScopeM) at ETH Zürich. We thank Dr. Nicholas Stadie for reading the manuscript.

Received: July 5, 2017

[1] a) D. V. Talapin, J.-S. Lee, M. V. Kovalenko, E V. Shevchenko, Chem. Rev. 2010, 110, 389; b) M. V. Kovalenko, Nat. Nanotechnol. 2015, 10, 994.

[2] O. Chen, L. Riedemann, F. Etoc, H. Herrmann, M. Coppey, M. Barch, C. T. Farrar, J. Zhao, O. T. Bruns, H. Wei, P. Guo, J. Cui, R. Jensen, Y Chen, D. K. Harris, J. M. Cordero, Z. Wang, A. Jasanoff, D. Fukumura, R. Reimer, M. Dahan, R. K. Jain, M. G. Bawendi, Nat. Commun. 2014, 5,5093

[3] a) A. L. Rogach, 'Semiconductor Nanocrystal Quantum Dots', Springer Vienna, Vienna, 2008 b) M. V. Kovalenko, L. Manna, A. Cabot, Z Hens, D. V. Talapin, C. R. Kagan, V. I. Klimov, A. L. Rogach, P. Reiss, D. J. Milliron, P. GuyotSionnnest, G. Konstantatos, W. J. Parak, T. Hyeon, B. A. Korgel, C. B. Murray, W. Heiss, ACS Nano 2015, 9, 1012.

[4] a) A. I. Ekimov, A. A. Onushchenko, Jetp Lett. 1981, 34, 345; b) A. L. Efros, Sov. Phys. Semicond. 1982, 16, 772; c) T. Itoh, T. Kirihara, J. Liminesc. 1984, 31-32, Part 1, 120.

[5] https://www.nrel.gov/pv/assets/images/efficiency-chart.png.

[6] a) M. M. Lee, J. Teuscher, T. Miyasaka, T. N. Murakami, H. J. Snaith, Science 2012, 338 , 643; b) M. A. Green, A. Ho-Baillie, H. J. Snaith, Nat. Photon. 2014, 8, 506; c) N.-G. Park, J. Phys. Chem. Lett. 2013, 4, 2423; d) M. Gratzel, Nature Mater. 2014, 13, 838

[7] L. Protesescu, S. Yakunin, M. I. Bodnarchuk, F. Krieg, R. Caputo, C. H. Hendon, R. X. Yang, A. Walsh, M. V. Kovalenko, Nano Lett. 2015, 15 , 3692.

[8] a) E. J. Juarez-Perez, Z. Hawash, S. R. Raga, L. K. Ono, Y. Qi, Energy Environ. Sci. 2016 , 9, 3406; b) B. Conings, J. Drijkoningen, N. Gauquelin, A. Babayigit, J. D'Haen, L. D'Olieslaeger, A. Ethirajan, J. Verbeeck, J. Manca, E. Mosconi, F. D. Angelis, H.-G Boyen, Adv. Energy Mater. 2015, 5, 1500477.

[9] a) K. Heidrich, W. Schafer, M. Schreiber, J. Sochtig, G. Trendel, J. Treusch, T. Grandke,
H. J. Stolz, Phys. Rev. B 1981, 24, 5642; b) M. Nikl, E. Mihokova, K. Nitsch, Solid State Commun. 1992, 84, 1089; c) M. Nikl, E. Mihokova, K. Nitsch, K. Polak, M. Rodova, M. Dusek, G. P. Pazzi, P. Fabeni, L. Salvini, M. Gurioli, Chem. Phys. Lett. 1994, 220, 14; d) R. Aceves, V. Babin, M. B. Flores, P. Fabeni, A. Maaroos, M. Nikl, K. Nitsch, G. P. Pazzi, R. P. Salas, I. Sildos, N. Zazubovich, S. Zazubovich, J. Lumin. 2001, 93, 27; e) V. Babin, P. Fabeni, M. Nikl, G. P. Pazzi, I. Sildos, N. Zazubovich, S. Zazubovich, Chem. Phys. Lett. 1999, 314, 31; f) P. Fabeni, G. P. Pazzi, M. Nikl, K. Nitsch, A. Scacco, F. Somma, S. Zazubovich, S. Santucci, A. R. Phani, 'Quantum confinement effects in the emission of thermally treated lead-doped caesium halides', Vol. 97, 1998; g) M. Nikl, E. Mihokova, K. Nitsch, F. Somma, C. Giampaolo, G. P. Pazzi, P. Fabeni, S. Zazubovich, Chem. Phys. Lett. 1999, 306, 280; h) M. Nikl, K. Nitsch, E. Mihokova, K. Polak, P. Fabeni, G. P. Pazzi, M. Gurioli, S. Santucci, R. Phani, A. Scacco, F. Somma, Physica E 1999, 4, 323; i) K. Nitsch, V. Hamplova, M. Nikl, K. Polak, M. Rodova, Chem. Phys. Lett. 1996, 258, 518; j) V. Babin, P. Fabeni, M. Nikl, K. Nitsch, G. P. Pazzi, S. Zazubovich, Phys. Status Solidi $B$ 2001, 226, 419; k) M. Nikl, K. Nitsch, J. Chval, F. Somma, A. R. Phani, S. Santucci, C. Giampaolo, P. Fabeni, G. P. Pazzi, X. Q. Feng, J. Phys. Condens. Matter 2000, 12, 1939; 1) F. Somma, M. Nikl, K. Nitsch, P. Fabeni, G. P. Pazzi, J. Lumin. 2001, 94, 169.

[10] H. L. Wells, Z. Anorg. Allg. Chem. 1893, 3, 195.

[11] C. K. Moller, Nature 1958, 182, 1436

[12] a) S. Sharma, N. Weiden, A. Weiss, Z. Phys. Chem 1992, 175, 63; b) D. M. Trots, S. V. Myagkota, J. Phys. Chem. Solids 2008, 69, 2520 ; c) C. C. Stoumpos, C. D. Malliakas, M. G. Kanatzidis, Inorg. Chem. 2013, 52, 9019; d) N. W. Surendra Sharma, Alarich Weiss, Z. Naturforsch. 1987, 42a, 1313; e) T. Sakudo, H. Unoki, Y. Fujii, J. Kobayashi, M. Yamada, Phys. Lett. A 1969, 28, 542; f) S. Hirotsu, S. Sawada, Phys. Lett. A 1969, 28, 762; g) N. TovborgJensen, J. Chem. Phys. 1969, 50, 559; h) J. A. Cape, R. L. White, R. S. Feigelson, J. Appl. Phys. 1969, 40, 5001; i) S. Hirotsu, J. Phys. Soc. Jpn. 1971, 31, 552; j) Y. Fujii, S. Hoshino, Y. Yamada, G. Shirane, Phys. Rev. B 1974, 9 , 4549; k) R. L. Armstrong, J. A. J. Lourens, J. D. Stroud, Phys. Rev. B 1976, 13, 5099; 1) M. Hidaka, Y. Okamoto, Y. Zikumaru, Phys. Status Solidi A 1983, 79, 263; m) C. K. Moller, Nature 1957, 180, 981; n) R. L. Armstrong, J. Magn. Reson. 1975, 20, 214; o) H. M. van Driel, R. L. Armstrong, Phys. Rev. B 1975, 12, 839.

[13] D. Weber, Z. Naturforsch. B 1978, 33, 1443.

[14] a) A. A. Zhumekenov, M. I. Saidaminov, M. A Haque, E. Alarousu, S. P. Sarmah, B. Murali, I. Dursun, X.-H. Miao, A. L. Abdelhady, T. Wu, O. F. Mohammed, O. M. Bakr, ACS Energy Lett. 2016, 32; b) G. Maculan, A. D. Sheikh, A. L. Abdelhady, M. I. Saidaminov, M. A. Haque, B. Murali, E. Alarousu, O. F. Mohammed, T. Wu, O. M. Bakr, J. Phys. Chem. Lett. 2015, 6, 3781; c) M. I. Saidaminov, A. L. Abdelhady, B. Murali, E. Alarousu, V. M. Burlakov, W. Peng, I. Dursun, L. Wang, Y. He, G. Maculan, A. Goriely, T. Wu, O. F. Mohammed, O. M. Bakr, Nat. Commun. 2015, 6, 8586; d) D. Shi, V. Adinolfi, R. Comin, M. Yuan, E. Alarousu, A. Buin, Y. Chen, S. Hoogland, A. Rothenberger, K. Katsiev, Y. Losovyj, X. Zhang, P. A. Dowben, O. F. Mohammed, E. H. Sargent, O. M. Bakr, Science 2015, 347, 519; e) D. N. Dirin, I. Cherniukh, S. Yakunin, Y. Shynkarenko, M. V. Kovalenko, Chem. Mater. 2016, 28, 8470; f) O. Nazarenko, S. Yakunin, V. Morad, I. Cherniukh, M. V. Kovalenko, NPG Asia Mater. 2017, 9, e373.

[15] L. C. Schmidt, A. Pertegas, S. GonzalezCarrero, O. Malinkiewicz, S. Agouram, G.
Minguez Espallargas, H. J. Bolink, R. E. Galian, J. Perez-Prieto, J. Am. Chem. Soc. 2014 136,850 .

[16] a) D. Zhang, S. W. Eaton, Y. Yu, L. Dou, P. Yang, J. Am. Chem. Soc. 2015, 137, 9230; b) D. Zhang, Y. Yu, Y. Bekenstein, A. B. Wong, A. P. Alivisatos, P. Yang, J. Am. Chem. Soc. 2016, 138, 13155; c) M. Imran, F. Di Stasio, Z. Dang, C. Canale, A. H. Khan, J. Shamsi, R. Brescia, M. Prato, L. Manna, Chem. Mater. 2016, 28, 6450; d) F. Di Stasio, M. Imran, Q. A Akkerman, M. Prato, L. Manna, R. Krahne, $J$. Phys. Chem. Lett. 2017, 2725.

[17] a) Q. A. Akkerman, S. G. Motti, A. R. Srimath Kandada, E. Mosconi, V. D’Innocenzo, G. Bertoni, S. Marras, B. A. Kamino, L. Miranda, F. De Angelis, A. Petrozza, M. Prato, L. Manna, J. Am. Chem. Soc. 2016, 138, 1010; b) J. Shamsi, Z. Dang, P. Bianchini, C. Canale, F. Di Stasio, R. Brescia, M. Prato, L. Manna, J. Am. Chem. Soc. 2016, 138, 7240; c) M. C. Weidman, M. Seitz, S. D. Stranks, W. A. Tisdale, ACS Nano 2016, 10, 7830; d) O. Vybornyi, S. Yakunin, M. V. Kovalenko, Nanoscale 2016, 8, 6278; e) L. Lv, Y. Xu, H. Fang, W. Luo, F. Xu, L. Liu, B. Wang, X. Zhang, D. Yang, W. Hu, A. Dong, Nanoscale 2016, 8, 13589; f) Y. Bekenstein, B. A. Koscher, S. W. Eaton, P. Yang, A. P. Alivisatos, J. Am. Chem. Soc. 2015, 137, 16008; g) J. A. Sichert, Y. Tong, N. Mutz, M. Vollmer, S. Fischer, K. Z. Milowska, R. García Cortadella, B. Nickel, C. Cardenas-Daw, J. K. Stolarczyk, A. S. Urban, J. Feldmann, Nano Lett. 2015 , 15,6521 ; h) V. A. Hintermayr, A. F. Richter, F. Ehrat, M. Döblinger, W. Vanderlinden, J. A Sichert, Y. Tong, L. Polavarapu, J. Feldmann, A. S. Urban, Adv. Mater. 2016, 28, 9478; i) Y. Tong, E. Bladt, M. F. Aygüler, A. Manzi, K. Z. Milowska, V. A. Hintermayr, P. Docampo, S. Bals, A. S. Urban, L. Polavarapu, J. Feldmann, Angew. Chem. Int. Ed. 2016, 55, 13887; j) A. Pan, B. He, X. Fan, Z. Liu, J. J. Urban, A. P. Alivisatos, L. He, Y. Liu, ACS Nano 2016, 10 , 7943; k) I. Levchuk, P. Herre, M. Brandl, A. Osvet, R. Hock, W. Peukert, P. Schweizer, E. Spiecker, M. Batentschuk, C. J. Brabec, Chem Commun. 2017, 53, 244.

[18] a) M. Isarov, L. Z. Tan, M. I. Bodnarchuk, M. V. Kovalenko, A. M. Rappe, E. Lifshitz, Nano Lett. 2017, doi:10.1021/acs.nanolett.7b02248; b) F. Zheng, L. Z. Tan, S. Liu, A. M. Rappe, Nano Lett. 2016, 16, 7316; c) Z.-G. Yu, J. Phys. Chem. Lett. 2016, 7, 3078; d) T. Etienne, E. Mosconi, F. De Angelis, J. Phys. Chem. Lett. 2016, 7, 1638; e) Z.-G. Yu, Phys. Chem. Chem. Phys. 2017, 19, 14907.

[19] J. De Roo, M. Ibáñez, P. Geiregat, G. Nedelcu, W. Walravens, J. Maes, J. C. Martins, I. Van Driessche, M. V. Kovalenko, Z. Hens, ACS Nano 2016, 10, 2071.

[20] J. Owen, Science 2015, 347, 615 .

[21] Z. Li, L. Kong, S. Huang, L. Li, Angew. Chem. Int. Ed. 2017, 56, 8134.

[22] A. Loiudice, S. Saris, E. Oveisi, D. T. L. Alexander, R. Buonsanti, Angew. Chem. Int. Ed. 2017, doi:10.1002/anie.201703703

[23] a) S. N. Raja, Y. Bekenstein, M. A. Koc, S Fischer, D. Zhang, L. Lin, R. O. Ritchie, P. Yang, A. P. Alivisatos, ACS Appl. Mater. Interfaces 2016, 8, 35523; b) M. Meyns, M. Perálvarez, A. Heuer-Jungemann, W. Hertog, M. Ibáñez, R. Nafria, A. Genç, J. Arbiol, M. V. Kovalenko, J. Carreras, A. Cabot, A. G. Kanaras, ACS Appl. Mater. Interfaces 2016, 8, 19579

[24] a) H. C. Wang, S. Y. Lin, A. C. Tang, B. P. Singh, H. C. Tong, C. Y. Chen, Y. C. Lee, T. L. Tsai, R. S. Liu, Angew. Chem. Int. Ed. 2016, 55, 7924; b) D. N. Dirin, L. Protesescu, D. Trummer, I. V. Kochetygov, S. Yakunin, F. Krumeich, N. P. Stadie, M. V. Kovalenko, Nano Lett. 2016, 16 , 5866; c) S. Huang, Z. Li, L. Kong, N. Zhu, A. Shan, L. Li, J. Am. Chem. Soc. 2016, 138, 5749. 
[25] J. Kang, L.-W. Wang, J. Phys. Chem. Lett. 2017, 489.

[26] Y. Guo, Q. Wang, W. A. Saidi, J. Phys. Chem. C 2017, 121, 1715 .

[27] a) R. E. Brandt, J. R. Poindexter, P. Gorai, R. C. Kurchin, R. L. Z. Hoye, L. Nienhaus, M. W. B. Wilson, J. A. Polizzotti, R. Sereika, R. Žaltauskas, L. C. Lee, J. L. MacManus-Driscoll, M. Bawendi, V. Stevanovic, T. Buonassisi, Chem. Mater. 2017, 29, 4667; b) H. Shi, M.H. Du, Phys. Rev. B 2014, 90, 174103; c) W.-J. Yin, T. Shi, Y. Yan, Appl. Phys. Lett. 2014, 104, 063903; d) K. X. Steirer, P. Schulz, G. Teeter, V. Stevanovic, M. Yang, K. Zhu, J. J. Berry, ACS Energy Lett. 2016, 1, 360; e) Z. Xiao, W. Meng, J. Wang, D. B. Mitzi, Y. Yan, Mater. Horiz. 2017, 4, 206.

[28] S. ten Brinck, I. Infante, ACS Energy Lett. 2016 , $1,1266$.

[29] F. Bertolotti, L. Protesescu, M. V. Kovalenko, S. Yakunin, A. Cervellino, S. J. L. Billinge, M. W. Terban, J. S. Pedersen, N. Masciocchi, A. Guagliardi, ACS Nano 2017, 11, 3819.

[30] M. A. Boles, M. Engel, D. V. Talapin, Chem. Rev. 2016, 116, 11220.

[31] Z. Yang, A. Surrente, K. Galkowski, A. Miyata, O. Portugall, R. J. Sutton, A. A. Haghighirad, H. J. Snaith, D. K. Maude, P. Plochocka, R. J. Nicholas, ACS Energy Lett. 2017, 1621

[32] A. Shinde, R. Gahlaut, S. Mahamuni, J. Phys. Chem. C 2017, doi:10.1021/acs.jpcc.7b02982.

[33] J. Li, L. Luo, H. Huang, C. Ma, Z. Ye, J. Zeng, H. He, J. Phys. Chem. Lett. 2017, 8, 1161.

[34] a) J. Li, L. Xu, T. Wang, J. Song, J. Chen, J. Xue, Y. Dong, B. Cai, Q. Shan, B. Han, H. Zeng, Adv. Mater. 2017, 29; b) T. Chiba, K. Hoshi, Y. J. Pu, Y. Takeda, Y. Hayashi, S. Ohisa, S. Kawata, J. Kido, ACS Appl. Mater. Interfaces 2017, 9, 18054; c) X. Zhang, C. Sun, Y. Zhang, H. Wu, C. Ji, Y. Chuai, P. Wang, S. Wen, C. Zhang, W. W. Yu, J. Phys. Chem. Lett. 2016 , 7, 4602; d) G. Li, F. W. Rivarola, N. J. Davis, S. Bai, T. C. Jellicoe, F. de la Pena, S. Hou, C. Ducati, F. Gao, R. H. Friend, N. C. Greenham, Z. K. Tan, Adv. Mater. 2016, 28, 3528.

[35] J. Pan, L. N. Quan, Y. Zhao, W. Peng, B. Murali, S. P. Sarmah, M. Yuan, L. Sinatra, N. M. Alyami, J. Liu, E. Yassitepe, Z. Yang, O. Voznyy, R. Comin, M. N. Hedhili, O. F. Mohammed, Z. H. Lu, D. H. Kim, E. H. Sargent, O. M. Bakr, Adv. Mater. 2016, 28, 8718.

[36] X. Dai, Z. Zhang, Y. Jin, Y. Niu, H. Cao, X. Liang, L. Chen, J. Wang, X. Peng, Nature 2014, 515, 96.

[37] H. C. Yoon, H. Kang, S. Lee, J. H. Oh, H. Yang, Y. R. Do, ACS Appl. Mater. Interfaces 2016, 8 , 18189.

[38] H. C. Yoon, J. H. Oh, S. Lee, J. B. Park, Y. R. Do, Sci. Rep. 2017, 7, 2808.
[39] a) A. Orte, J. M. Alvarez-Pez, M. J. RuedasRama, ACS Nano 2013, 7, 6387; b) L. Damalakiene, V. Karabanovas, S. Bagdonas, R. Rotomskis, Int. J. Mol. Sci. 2016, 17, 473; c) K. Hoffmann, T. Behnke, D. Drescher, J. Kneipp, U. Resch-Genger, ACS Nano 2013, 7, 6674

[40] a) K. Hoffmann, T. Behnke, D. Drescher, J. Kneipp, U. Resch-Genger, in 'Single Molecule Spectroscopy and Imaging', Vol. 7905, Eds.: J. Enderlein, Z. K. Gryczynski, R. Erdmann, Spie-Int Soc Optical Engineering, Bellingham, 2011; b) P. Kumar, J. Dwivedi, B. K. Gupta, J. Mater. Chem. C 2014, 2, 10468; c) P. Kumar, K. Nagpal, B. K. Gupta, ACS Appl. Mater. Interfaces 2017, 9, 14301; d) S. P. McGrew, Google Patents, 2004, No. US6692031B2; e) P. A. Carr, J. L. Conroy, O. O. Soyemi, Google Patents, 2014, No. US20140001351A1; f) G. I Jones, S. Burke, P. Mcdonald, Google Patents, 2003, No WO2003105075A1.

[41] L. Protesescu, S. Yakunin, M. I. Bodnarchuk, F. Bertolotti, N. Masciocchi, A. Guagliardi, M. V. Kovalenko, J. Am. Chem. Soc. 2016, 138, 14202.

[42] N. L. Pickett, N. C. Gresty, M. A. Hines, SID Symp. Dig. Tec. 2016, 47, 425

[43] Q. Chen, F. Chen, Y. Yan, Bioresources 2013, 8, 1603885.

[44] a) S. Yakunin, L. Protesescu, F. Krieg, M. I Bodnarchuk, G. Nedelcu, M. Humer, G. De Luca, M. Fiebig, W. Heiss, M. V. Kovalenko, Nat. Commun. 2015, 6, 8056; b) Y. Wang, X. Li, J. Song, L. Xiao, H. Zeng, H. Sun, Adv. Mater. 2015, 27, 7101 .

[45] C. Dang, A. Nurmikko, Mrs Bull 2013, 38, 737.

[46] C. Dang, J. Lee, C. Breen, J. S. Steckel, S Coe-Sullivan, A. Nurmikko, Nat. Nanotechnol. 2012, 7, 335.

[47] a) S. Ithurria, M. D. Tessier, B. Mahler, R. P. Lobo, B. Dubertret, A. L. Efros, Nature Mater. 2011, 10, 936; b) M. D. Tessier, P. Spinicelli, D. Dupont, G. Patriarche, S. Ithurria, B. Dubertret, Nano Lett. 2014, 14, 207; c) C. She, I. Fedin, D. S. Dolzhnikov, A. Demortiere, R. D. Schaller, M. Pelton, D. V. Talapin, Nano Lett. 2014, 14, 2772.

[48] J. Q. Grim, S. Christodoulou, F. Di Stasio, R. Krahne, R. Cingolani, L. Manna, I. Moreels, Nat. Nanotechnol. 2014, 9, 891.

[49] Y. Xu, Q. Chen, C. Zhang, R. Wang, H. Wu, X. Zhang, G. Xing, W. W. Yu, X. Wang, Y. Zhang, M. Xiao, J. Am. Chem. Soc. 2016, 138, 3761.

[50] H. Zhu, Y. Fu, F. Meng, X. Wu, Z. Gong, Q. Ding, M. V. Gustafsson, M. T. Trinh, S. Jin, X. Y. Zhu, Nature Mater. 2015, 14, 636

[51] N. Oh, B. H. Kim, S.-Y. Cho, S. Nam, S. P. Rogers, Y. Jiang, J. C. Flanagan, Y. Zhai, J.-H. Kim, J. Lee, Y. Yu, Y. K. Cho, G. Hur, J. Zhang, P. Trefonas, J. A. Rogers, M. Shim, Science 2017, 355, 616 .
[52] a) S. Wang, D. B. Mitzi, C. A. Feild, A. Guloy, J. Am. Chem. Soc. 1995, 117, 5297; b) D. B. Mitzi, Chem. Mater. 1996, 8, 791; c) J. P. Steadman, R. D. Willett, Inorg. Chim. Acta 1970, 4, 367; d) C. Bellitto, P. Day, J. Mater. Chem. 1992, 2, 265.

[53] a) J. Calabrese, N. L. Jones, R. L. Harlow, N. Herron, D. L. Thorn, Y. Wang, J. Am. Chem. Soc. 1991, 113, 2328; b) C. C. Stoumpos, D. H. Cao, D. J. Clark, J. Young, J. M. Rondinelli, J. I. Jang, J. T. Hupp, M. G. Kanatzidis, Chem. Mater. 2016, 28, 2852.

[54] a) B. Saparov, D. B. Mitzi, Chem. Rev. 2016, 116, 4558; b) A. Lemmerer, D. G. Billing, Cryst. Eng. Comm. 2012, 14, 1954; c) A. H Slavney, R. W. Smaha, I. C. Smith, A. Jaffe, D. Umeyama, H. I. Karunadasa, Inorg. Chem. 2017, 56, 46.

[55] Z. Wang, Z. Shi, T. Li, Y. Chen, W. Huang, Angew. Chem. Int. Ed. 2017, 56, 1190.

[56] a) D. H. Fabini, J. G. Labram, A. J. Lehner, J. S Bechtel, H. A. Evans, A. Van der Ven, F. Wudl, M. L. Chabinyc, R. Seshadri, Inorg. Chem. 2017, 56, 11; b) S. Chakraborty, W. Xie, N. Mathews, M. Sherburne, R. Ahuja, M. Asta, S. G. Mhaisalkar, ACS Energy Lett. 2017, 2, 837; c) F. Giustino, H. J. Snaith, ACS Energy Lett. 2016, $1,1233$.

[57] a) A. H. Slavney, T. Hu, A. M. Lindenberg, H I. Karunadasa, J. Am. Chem. Soc. 2016, 138, 2138; b) G. Volonakis, A. A. Haghighirad, R. L. Milot, W. H. Sio, M. R. Filip, B. Wenger, M. B. Johnston, L. M. Herz, H. J. Snaith, F. Giustino, J. Phys. Chem. Lett. 2017, 8, 772; c) X.-G. Zhao, D. Yang, Y. Sun, T. Li, L. Zhang, L. Yu, A. Zunger, J. Am. Chem. Soc. 2017, 139, 6718; d) X.-G. Zhao, J.-H. Yang, Y. Fu, D. Yang, Q. Xu, L. Yu, S.-H. Wei, L. Zhang, J. Am. Chem. Soc. 2017, 139, 2630; e) C. N. Savory, A. Walsh, D. O. Scanlon, ACS Energy Lett. 2016, 1, 949.

[58] W. Meng, X. Wang, Z. Xiao, J. Wang, D. B. Mitzi, Y. Yan, J. Phys. Chem. Lett. 2017, 2999.

[59] N. Sakai, A. A. Haghighirad, M. R. Filip, P. K. Nayak, S. Nayak, A. Ramadan, Z. Wang, F. Giustino, H. J. Snaith, J. Am. Chem. Soc. 2017, $139,6030$.

[60] W. Lin, C. C. Stoumpos, Z. Liu, S. Das, O. Y. Kontsevoi, Y. He, C. D. Malliakas, H. Chen, B. W. Wessels, M. G. Kanatzidis, ACS Photonics 2017, doi.10.1021/acsphotonics.7b00388.

[61] A. Emly, E. Kioupakis, A. Van der Ven, Chem. Mater. 2013, 25, 4663.

[62] X. Zhang, K. Liu, J.-Q. He, H. Wu, Q.-Z Huang, J.-H. Lin, Z.-Y. Lu, F.-Q. Huang, Sci. Rep. 2015, 5, 15910. 